\title{
EFEITO DA POLINIZAÇÃO DIRIGIDA ENTRE PORTA-ENXERTOS DE MACIEIRA (Malus sp.) NA FRUTIFICAÇÃO EFETIVA E NO DESENVOLVIMENTO DE FRUTOS EM SÃO JOAQUIM-SC ${ }^{1}$
}

\author{
ADRIANA CIBELE DE MESQUITA DANTAS², JÚLIO CÉSAR DE OLIVEIRA NUNES³, \\ EMÍLIO BRIGHENTI ${ }^{4}$, LUIZ GONZAGA RIBEIRO ${ }^{4}$, RUBENS ONOFRE NODARI ${ }^{5}$
}

\begin{abstract}
RESUMO - Com o objetivo específico de obter uma população segregante, visando à avaliação na frutificação efetiva, quantidade de sementes normais e peso e diâmetro de frutos oriundos de polinização aberta e dirigida, foram realizados cruzamentos entre dois portaenxertos de macieira, Marubakaido (Malus prunifolia Borkh.) e M.9 (Malus pumila Mill.) na Estação Experimental de São Joaquim EPAGRI/SC. 'Marubakaido' apresentou florescimento mais precoce e mais prolongado que a cultivar M.9. A percentagem de frutificação efetiva, para o porta-enxerto 'M.9' usado como progenitor feminino, foi de $26 \%$ e $32 \%$, e usado como doador de pólen, foi de $5 \%$ e $25 \%$, no anos de 1999 e 2000, respectivamente. Foram encontrados frutos deformados nos cruzamentos de 'M.9' X 'Marubakaido' e com um maior número de sementes atípicas quando comparadas ao sistema de polinização aberta. O mesmo não ocorreu no cruzamento recíproco. O peso e o diâmetro dos frutos foram maiores quando houve a polinização dirigida em 'M.9', o mesmo não acontecendo com 'Marubakaido', comparativamente à polinização aberta. A análise via contrastes ortogonais revelou valores de F significativos também para número de sementes normais e anormais frente aos dois sistemas de polinização em 'M.9'.
\end{abstract}

Termos para indexação: Melhoramento genético, polinização, Malus pumilla, Malus prunifolia.

\section{EFFECT OF THE ARTIFICIAL POLLINATION AMONG APPLE ROOTSTOCK (Malus spp.) IN THE EFFECTIVE FRUIT SET AND FRUIT DEVELOPMENT IN SÃO JOAQUIM/SC.}

SUMMARY - This work had as objective to evaluate the fruit set, fruit weight and diameter and amount of normal and atypical seeds of two apple rootstocks in both open and artificial pollination conditions. Crosses among 'Marubakaido' (Malus prunifolia Borkh.) and 'M.9' (Malus pumila Mill) and reciprocal were performed at Estação Experimental de São Joaquim - EPAGRI/SC. 'Marubakaido' required least cool temperatures to blooming and kept longer than M.9 cultivar. The percentage of effective fruit set when 'M.9' were used as female was $26 \%$ and $32 \%$ and when it was used as pollen donor, $5 \%$ e $25 \%$, in 1999 and 2000, respectively. The cross 'M.9' X 'Marubakaido' produced deformed fruits, with a higher number of atypical seeds, in comparison with the open pollination system. The same results did not occurred in the reciprocal cross. The 'M.9' fruit weight and diameter were larger in the artificial crosses than in those produced by open pollination. No differences among pollination systems for the same variables were found in 'Marubakaido'. In addition, orthogonal contrast analyses revealed significant $F$ values for number of normal seeds, number of atypical seeds when pollination systems in 'M.9' were compared.

Index terms: Breeding and genetics, pollination, Malus pumila, Malus prunifolia.

\section{INTRODUÇÃO}

Vários programas de melhoramento têm sido eficientes na geração de porta-enxertos de macieira, destacando-se os programas HRI - East Malling que se concentra na produção de novos porta-enxertos necessários à Inglaterra (Webster et al., 1997). Existem, ainda, programas na Polônia (Zagaja, 1980), Canadá (Granger et al., 1992; Elrving et al., 1993), Alemanha (Fischer, 1997), Suécia (Trajkovski e Anderson, 1988) e Estados Unidos (Cummins e Aldwinckle, 1994). Os novos genótipos têm sido obtidos com ênfase na seleção de porta-enxertos anões com boa tolerância ao frio, além de resistência a pragas e doenças (Cummins e Aldwinckle, 1994).

O porta-enxerto Marubakaido (Malus prunifolia Borkh.) é de origem japonesa, sendo bastante utilizado como portaenxerto comercial no Japão e na Europa (Bessho et al., 1993), bem como no Brasil, por ser vigoroso, apresentar resistência à podridão-do-colo, com relativa resistência a Rosellinia sp. e muito sensível a viroses (Denardi, 1986). Um outro porta-enxerto, o M.9 (Malus pumila Miller) (Ishikawa et al., 1993), foi introduzido mais recentemente em pomares comerciais na Holanda (Wertheim, 1997), Inglaterra (Webster, 1997) e França (Masseron e Roche, 1993), onde é bastante utilizado em plantios de alta densidade, por causa de sua precocidade e produtividade (Ferree e Carlson, 1986; Webster, 1997).

Contudo, estes dois porta-enxertos apresentam vários problemas, tais como difícil propagação por estaca, pouca adaptabilidade em solos fracos, suscetibilidade a pragas e

1 (Trabalho 133/2000). Recebido: 12/07/2000. Aceito para publicação: 11/05/2001.

2 Doutoranda em Fruticultura de Clima Temperado, FAEM/UFPEL, Pelotas, RS

3 Mestrando em Recursos Genéticos, CCA/UFSC, Florianópolis, SC

4 Pesquisadores da Estação Experimental de São Joaquim/EPAGRI, SC

5 Prof. PhD. Genética e Melhoramento Vegetal, Recursos Genéticos, UFSC, SC 
doenças e incompatibilidade de enxertia (Bessho et al., 1993). Por outro lado, existe interesse dos produtores de maçãs da Região Sul do Brasil, em relação à utilização de um porta-enxerto clonal que reúna características como a imunidade ao Eriosoma lanigerum (pulgão lanígero), ausência de rebrotamento no nível do colo, espectro de vigor entre semi-anões a vigorosos, precocidade, alta produtividade, alta resistência a Phytophtora cactorum (podridão-do-colo) e, em especial, tolerância a altos níveis de alumínio no solo (Denardi, 1986). Para gerar tal clone, cruzamentos entre variedades de porta-enxertos têm sido realizados, incluindo os dois mencionados.

Assim, o objetivo deste trabalho foi avaliar a frutificação efetiva, assim como parâmetros relacionados ao desenvolvimento dos frutos e o número de sementes normais e atípicas obtidas em uma população $\mathrm{F}_{1}$, oriundos de polinização aberta e dirigida, envolvendo os porta-enxertos M.9 e Marubakaido nos anos de 1999 e 2000. Com a obtenção de uma população segregante, será possível não só a seleção de clones às características desejáveis, mas também a construção de mapas genéticos com marcadores moleculares, identificando regiões do genoma que contêm genes de resistência e/ou tolerância ao alumínio e de resistência a Phytophtora cactorum (podridão-do-colo).

\section{MATERIAL E MÉTODOS}

O experimento foi realizado na Estação Experimental de São Joaquim - EPAGRI/SC, utilizando-se de dois porta-enxertos de macieira, Marubakaido e M.9. Foram realizadas duas combinações de cruzamentos: 'M.9' X 'Marubakaido' e o cruzamento recíproco. O número de flores polinizadas foi de 2000 para o cruzamento 'M9' X 'Marubakaido' no ano de 1999 e de 1914 no ano de 2000. Para o cruzamento recíproco, 'Marubakaido' X 'M.9', foram feitas 500 polinizações em 1999 e 1675 em 2000. Imediatamente após a emasculação feita no estádio de balão, as flores foram polinizadas, passando-se levemente sobre o estigma o dedo indicador contendo o pólen. Em seguida, foi feito o ensacamento das flores com papel encerado. As demais flores ficaram livres para que ocorresse a polinização aberta não só de variedades porta-enxertos como também de copa existente nas proximidades.

Aos 80 dias após a polinização, determinou-se a frutificação efetiva, através da fórmula: frutificação efetiva $=\left(\mathrm{n}^{0}\right.$ de frutos $/ \mathrm{n}^{0}$ de flores polinizadas) X 100. Coletaram-se também 25 frutos, sendo cinco por árvore, tanto do sistema de polinização dirigida como o de polinização aberta. Os frutos de polinização aberta foram retirados ao acaso para compor um padrão nas comparações com os frutos da polinização dirigida. Usando-se um paquímetro, foram medidos os diâmetros dos frutos e, com a balança analítica, pesou-se cada um dos frutos coletados. Foram avaliados também o número médio de sementes/fruto e o número de sementes normais e atípicas. Foram consideradas sementes atípicas aquelas que apresentavam apenas o tegumento desenvolvido, ou aquelas abortadas (Figura 1a). Os dados de classificação foram submetidos à análise do $\chi^{2}$ e os demais dados à Análise da Variância, com a decomposição dos graus de liberdade baseados nos componentes ortogonais (Steel e Torrie, 1980).

\section{RESULTADOS E DISCUSSÃO}

O período de floração ou de abertura de flores nos dois anos apresentou diferenças entre as duas cultivares avaliadas. O porta-enxerto 'Marubakaido' foi o primeiro a florescer, permanecendo em torno de 21 dias liberando pólen. O portaenxerto 'M.9' apresentou um período de florescimento que durou 15 dias (Tabela 1). Em decorrência do curto período de sobreposição de floração, em torno de 10 dias, foi necessária a estocagem de pólen do 'Marubakaido' para efetuar as polinizações em flores 'M.9'.

As florações foram uniformes e abundantes nos dois porta-enxertos, nos dois anos de avaliação, com uma boa produção de pólen de ambas as cultivares. O porta-enxerto M.9 foi mais tardio em termos de início de florescimento nos anos de 1999 e 2000 em relação ao porta-enxerto Marubakaido mesmo antecipando a época de floração em torno de 15 dias no ano de 2000. Esta antecipação mais pronunciada em relação ao 'Marubakaido' sugere que esta cultivar é mais sensível aos fatores climáticos locais que possivelmente estejam interferindo na fisiologia da planta para superação de sua dormência. O portaenxerto Marubakaido caracterizou-se por ter menor exigência em frio que a cultivar M.9, pois apresentou florescimento mais precoce (Tabela 1). Existem diferenças genéticas entre os portaenxertos em relação às exigência de frio para a superação da dormência (Ferree e Carlson, 1986; Faust et al., 1976; Faust, 1989), onde o porta-enxerto M.9 caracteriza-se por ter baixa exigência em frio. Esta maior ou menor exigência em frio para superar a dormência, varia de acordo com a espécie e dentro da espécie (Champagnat, 1992; Soltész, 1997), como de fato corroboram os resultados deste trabalho.

A maioria das cultivares de macieira necessita de invernos com acúmulos de horas de frio no mínimo de 800 horas com temperaturas iguais ou inferiores a $7,2^{\circ} \mathrm{C}$ para apresentar boa brotação e floração (Hauagge e Tsuneta, 1998), porém constantes, em detrimento da ocorrência de temperaturas altas $\left(20^{\circ} \mathrm{C}\right)$ alternadas a períodos de temperaturas extremamente baixas $\left(0^{\circ} \mathrm{C}\right)$. Tais flutuações são comuns na maioria das regiões onde se cultiva maçã no Brasil. Entretanto, trabalhos de melhoramento genético têm possibilitado a obtenção de cultivares bem menos exigentes em frio (Bender, 1986; Seif e Nassan, 1992; Petri et al., 1996). O acúmulo de horas com temperaturas abaixo ou igual a $7,2^{\circ} \mathrm{C}$ em São Joaquim-SC, acumuladas no mês de agosto atingiu 937 horas e 921 horas, nos anos de 1999 e 2000, respectivamente. Estas quantidades já seriam suficientes para que a dormência das gemas fosse superada naturalmente, proporcionando uma floração abundante nas variedades estudadas (Tabela 2).

Em geral, a temperatura máxima foi em torno de $17^{\circ} \mathrm{C}$ para os dois anos, e a mínima não ultrapassou $5^{\circ} \mathrm{C}$ (Tabela 3). Em geral, para as cultivares de macieira, a temperatura não deve ultrapassar $21^{\circ} \mathrm{C}$, devendo as temperaturas baixas permanecerem por um período superior a 10 dias. Constatou-se que a temperatura média das médias nos três meses, nos dois anos, foi de $11^{\circ} \mathrm{C}$ e que houve um curto período de floração nos portaenxertos, mas de forma concentrada e homogênea. Este comportamento deve-se ao somatório de unidades de frio satisfatório nestes anos, pois, caso contrário, a floração seria prolongada e desuniforme (Camargo, 1973). Pelegrin (1976) relatou uma floração mais prolongada em macieira no Planalto 
Catarinense, apresentando uma variação de três a seis semanas, podendo estender-se por até dois meses.

Intrigante também foi o fato de que, no ano de 2000, onde ocorreu uma antecipação do florescimento de ambos os porta-enxertos avaliados, tanto a média das mínimas quanto a média das máximas foi inferior aos respectivos valores medidos em 1999 (Tabela 3). Este fato demonstra novamente a íntima relação entre temperatura e superação da dormência.
Em relação às chuvas, houve maior precipitação no mês de outubro, coincidente com a época de plena florada das cultivares testadas, totalizando $127,7 \mathrm{~mm}$ e 281,5 mm de lâmina de água nos anos de 1999 e 2000, respectivamente. A antecipação da plena floração pelo 'M.9', no ano de 2000, foi coincidente com a duplicação da quantidade de chuvas nos meses de agosto e setembro em 2000, comparativamente a 1999 (Tabela 2). Mas os períodos chuvosos durante a floração prejudicam a polinização,

TABELA 1 - Período de floração de dois porta-enxertos de macieira, na EPAGRI, São Joaquim - SC.

\section{IC L O S}

\begin{tabular}{|c|c|c|c|c|c|c|c|c|c|c|c|c|}
\hline \multirow[t]{2}{*}{ Porta-enxertos } & \multicolumn{6}{|c|}{ setembro } & \multicolumn{6}{|c|}{ outubro } \\
\hline & 5 & 10 & 15 & 20 & 25 & 30 & 5 & 10 & 15 & 20 & 25 & 30 \\
\hline
\end{tabular}

M arubakaido

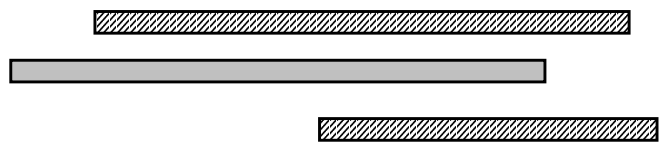

M.9

$\overline{\square / 7}-1999 \square-2000$

TABELA 2 - Precipitação, horas de frio e horas de frio acumuladas dos anos de 1999 e 2000 e dos últimos 20 anos, coletados na Estação Meteorológica da EPAGRI, São Joaquim - SC.

Precipitação Horas de frio

( $\mathrm{m} \mathrm{m}$ )

M eses

A gos to

$199922000 \quad 20$ anos

$\mathrm{S}$ ete $\mathrm{m}$ bro

O utubro

38,3

$84,8 \quad 166,6$

95,3

188,2

$127,7 \quad 281,5$

172,3

167,5

129

$\left(<7,2^{0} \mathrm{C}\right)$

Horas de frio acum ladas

TABELA 3 - Temperaturas média das máximas, média das mínimas e média das médias, dos meses de agosto, setembro e outubro de 1999 e 2000 e dos últimos 20 anos coletados na Estação Meteorológica da EPAGRI, São Joaquim - SC.

\begin{tabular}{|c|c|c|c|c|c|c|c|c|c|}
\hline \multirow{3}{*}{ Meses } & \multicolumn{9}{|c|}{ Tem peratura $\left({ }^{0} \mathrm{C}\right)$} \\
\hline & \multicolumn{3}{|c|}{ Máxim a } & \multicolumn{3}{|c|}{ M ínim a } & \multicolumn{3}{|c|}{ M édia } \\
\hline & 1999 & 2000 & 20 anos & 1999 & 2000 & 20 anos & 1999 & 2000 & 20 anos \\
\hline A gosto & 17,2 & 16,2 & 16,4 & 6,3 & 5,7 & 6,8 & 10,6 & 10,0 & 10,7 \\
\hline S etem bro & 17,8 & 16,1 & 17,7 & 7,1 & 6,7 & 7,8 & 11,8 & 10,6 & 11,8 \\
\hline Outubro & 16,2 & 19,6 & 19,3 & 7,3 & 10,7 & 9,3 & 11,2 & 14,6 & 13,2 \\
\hline
\end{tabular}

TABELA 4 - Número de flores polinizadas e percentagem de frutificação efetiva em cruzamentos entre dois porta-enxertos. EPAGRI, São Joaquim - SC.

\begin{tabular}{|c|c|c|c|c|}
\hline \multirow{2}{*}{ Intercruzam entos } & \multicolumn{2}{|c|}{ Númerode flores polinizadas } & \multicolumn{2}{|c|}{ Frutifica ção efetiva (\%) } \\
\hline & 1999 & 2000 & 1999 & 2000 \\
\hline 'M.9'X 'M arubakaido' & 3000 & 1914 & 25 & 32 \\
\hline 'M arubakaido' X 'M .9" & 500 & 1675 & 5 & 18 \\
\hline
\end{tabular}


TABELA 5 - Peso e diâmetro de frutos da polinização dirigida e aberta em dois porta-enxertos de macieira. EPAGRI, São Joaquim - SC.

\begin{tabular}{lcc|cc}
\hline \multirow{2}{*}{ Genótipos } & \multicolumn{2}{c|}{ Pesodos frutos $(\mathbf{g})$} & \multicolumn{3}{|c}{ Diâmetro dos frutos (m m ) } \\
\cline { 2 - 5 } & $\mathbf{1 9 9 9}$ & $\mathbf{2 0 0 0}$ & $\mathbf{1 9 9 9}$ & $\mathbf{2 0 0 0}$ \\
\hline 'M .9' X 'M arubakaido' & $15,0 \mathrm{a}$ & $61,2 \mathrm{a}$ & $32,5 \times 30,2 \mathrm{a}$ & $55,0 \times 47,0 \mathrm{a}$ \\
'M .9' & $14,3 \mathrm{~b}$ & $54,6 \mathrm{~b}$ & $28,8 \times 30,0 \mathrm{~b}$ & $52,6 \times 44,0 \mathrm{~b}$ \\
'M arubakaido' & $1,1 \mathrm{c}$ & $2,2 \mathrm{c}$ & $11,0 \times 11,5 \mathrm{c}$ & $14,4 \times 15,0 \mathrm{c}$ \\
M arubakaidoXM 9 & na & $1,9 \mathrm{c}$ & na & $15,0 \times 16,0 \mathrm{c}$ \\
\hline
\end{tabular}

na $=$ não avaliado

Médias na mesma coluna seguidas pela mesma letra não diferem pelo teste Duncan (5\%).

TABELA 6 - Tabela de contingência entre sistemas de polinização e tipos de sementes das cultivares M9 e Marubakaido. EPAGRI, São Joaquim - SC, 2000.

\begin{tabular}{clcccc}
\hline & Polinizaça o & Sementes Normais & Sementes A típicas & Totais & $\chi^{2}$ \\
\hline M 9 & A berta & $56(37,0)$ & $68(86,9)$ & 124 \\
& D irigida & $19(37,9)$ & $108(89,0)$ & 127 & 27,312 \\
\hline Totais & 75 & 176 & 251 & 92 \\
\hline M a rubakaido & A berta & $41(40,3)$ & $51(51,7)$ & 70 & 0,047 \\
& D irigida & $30(30,7)$ & $40(39,3)$ & 162 & 0 \\
& Totais & 71 & 91 & & \\
\hline
\end{tabular}

TABELA 7 - Graus de liberdade e quadrados médios dos contrastes polinização aberta vs polinização dirigida para cinco variáveis avaliadas. Epagri, São Joaquim - SC, 1999/2000.

\begin{tabular}{|c|c|c|c|c|c|c|}
\hline \multirow[b]{3}{*}{ Contrastes } & \multicolumn{6}{|c|}{ Quadrados Médios } \\
\hline & \multirow[b]{2}{*}{ G L } & \multicolumn{2}{|c|}{ Frutos } & \multicolumn{2}{|c|}{ Sementes } & \multirow{2}{*}{$\begin{array}{l}\text { Carpelos } \\
\text { com sementes } \\
\left(n^{\circ}\right)\end{array}$} \\
\hline & & $\begin{array}{l}\text { Peso } \\
\text { (g) }\end{array}$ & $\begin{array}{c}\text { Diâ m etro } \\
(\mathrm{m} \mathrm{m})\end{array}$ & $\begin{array}{c}\text { Norma is } \\
\left(n^{\circ}\right)\end{array}$ & $\begin{array}{c}\text { A típicas } \\
\left(\mathrm{n}^{\circ}\right)\end{array}$ & \\
\hline $\begin{array}{l}\text { M.9 PA vs. } \\
\text { 'M 9'x'M arubakaido' }\end{array}$ & 1 & $106,3411 * *$ & $0,151 * * *$ & $0,747 * * *$ & $0,448 * *$ & $0,214 * * *$ \\
\hline $\begin{array}{l}\text { 'M arubakaido' PA vs. } \\
\text { 'M arubakaido'x'M .9' }\end{array}$ & 1 & $0,134 \mathrm{~ns}$ & $0,010 \mathrm{~ns}$ & $0,013 \mathrm{~ns}$ & $0,001 \mathrm{~ns}$ & $0,008 \mathrm{~ns}$ \\
\hline PA vs. PD & 1 & $57,020 * *$ & $0,120 * *$ & $0,282 *$ & $0,214^{*}$ & $0,549 * *$ \\
\hline
\end{tabular}

PA = Polinização aberta (M9+Marubakaido); PD = Polinização dirigida (M9xMarubakaido e recíproco)

$*, * *, * * *$, ns. Significativo a $0,05 \geq \mathrm{P}>0,01 ; 0,01 \geq \mathrm{P}>0,001 ; \mathrm{P} \leq 0,001$; não significativo, respectivamente.

diminuindo o período receptivo dos estigmas e causando danos mecânicos às flores (Rom, 1970; Childers, 1976).

A percentagem de frutificação efetiva, para o portaenxerto M.9 usado como progenitor feminino, foi de $26 \%$ e $32 \%$, e usado como doador de pólen foi de $5 \%$ e $25 \%$, nos anos de 1999 e 2000, respectivamente (Tabela 4). A frutificação efetiva em ambos os cruzamentos pode estar associada a fatores genéticos de incompatibilidade entre cruzamentos ou associadas a fatores ambientais, como variações climáticas, com alternância de frio e calor após a polinização, que afetam a penetração e crescimento do tubo polínico, como já verificado anteriormente por William e Maier (1977) e Soltész (1997). Grauslund (1996) verificou que a germinação de pólen é satisfatória com $25 \%$ de frutificação efetiva.

Em ambos os anos avaliados, a frutificação efetiva do cruzamento 'Marubakaido' X 'M9' (5 e 18\%, respectivamente) foi menor que no cruzamento recíproco (25 e $32 \%$, respectivamente, Tabela 4), provavelmente devido a uma maior incompatibilidade, embora o cruzamento seja interespecífico. Incompatibilidade intra-específica foi verificada anteriormente, por Manganaris e Alston (1987) e Dayton (1974), com cruzamentos entre cultivares-copa.

Neste trabalho, observou-se que o acúmulo de unidades de frio foi suficiente, mas houve quedas bruscas de temperatura, chegando a $0^{\circ} \mathrm{C}$, após a floração, podendo ser um dos fatores responsáveis pela baixa frutificação efetiva. Anteriormente, Petri e Pascoal (1981) e Schramm (1985) verificaram que cruzamentos com baixa frutificação também estavam associados a fatores climáticos como baixas temperaturas após a floração, carência em número de horas de frio no período de dormência ou deficiência de caráter fisiológico. 


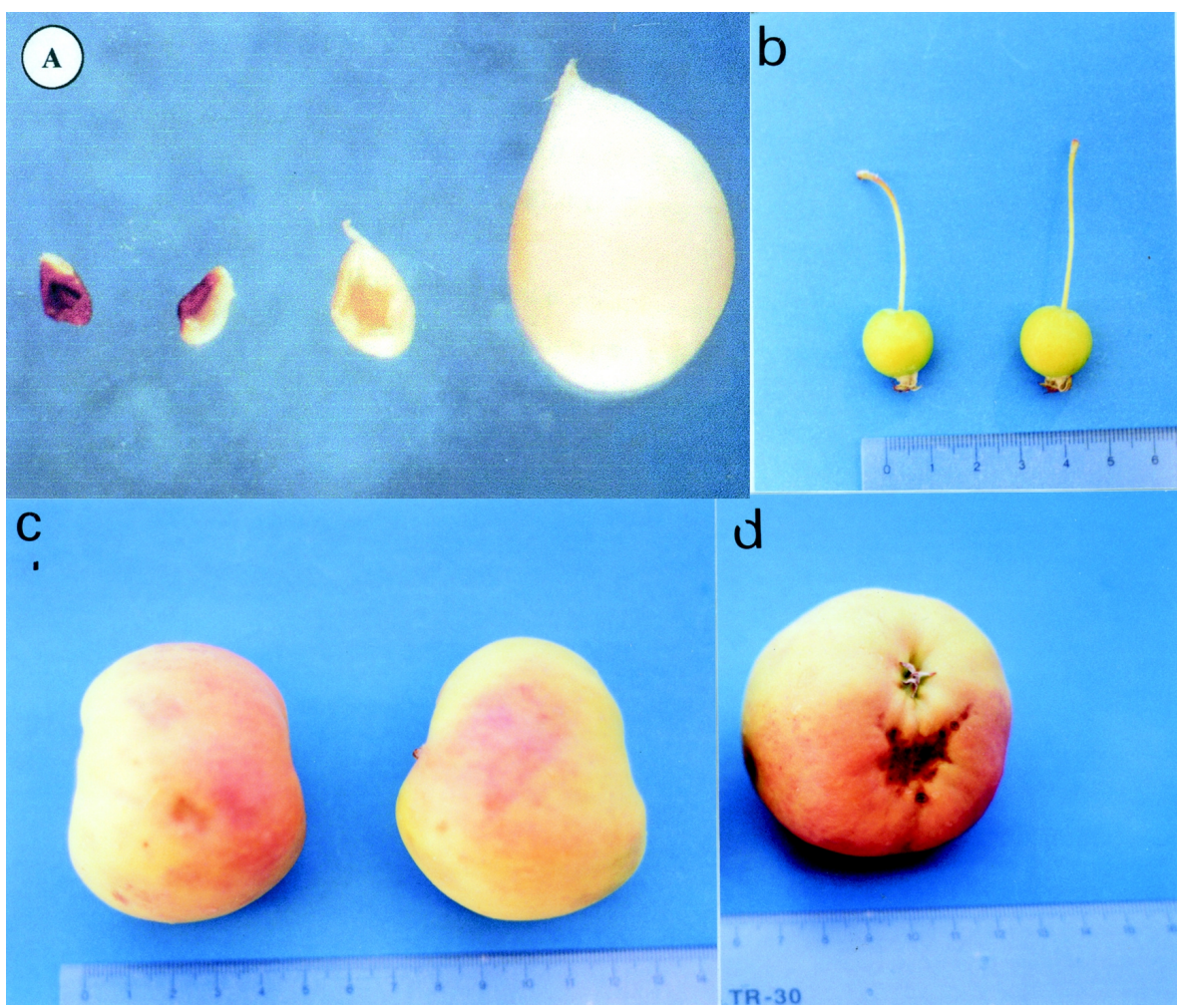

FIGURA 1 - Sementes e frutos dos porta-enxertos de macieira M.9 e Marubakaido. A) Sementes atípicas (três primeiras) e normal (direita); b) Frutos de 'Marubakaido' de polinização aberta (esquerda) e dirigida (direita); c) Frutos de ‘M.9' de polinização aberta (esquerda) e de polinização dirigida (direita); d) Fruto de 'M.9' deformado.

Contudo, os cruzamentos realizados foram entre diferentes espécies do mesmo gênero. Esta especiação entre as duas espécies deve estar contribuindo para que estes valores de frutificação efetiva não sejam mais altos. O fato da obtenção de sementes significa que o processo evolutivo ainda não separou totalmente estas duas espécies.

No cruzamento 'M.9' X 'Marubakaido', foi encontrada também uma maior quantidade de frutos deformados $(50 \%$, Figuras 1c e 1d), comparativamente à polinização aberta em M.9 (20\%) em 'Marubakaido' (0\%), que produziu frutos bem redondos, simétricos e uniformes (Figura 1b). As variações no tamanho do fruto são devidas principalmente às diferenças no conteúdo de sementes, onde ocorre uma polinização parcial ou inadequada (Murneek, 1930).

Os valores médios de peso e de diâmetro de frutos estão na Tabela 5. Para 'M.9', o teste de separação de médias utilizado após a Análise da Variância indicou que tanto o peso quanto o diâmetro dos frutos foram maiores quando a polinização foi dirigida, comparativamente à polinização aberta, nos dois anos avaliados. Comportamento diferente foi revelado pelos frutos de 'Marubakaido', pois não houve diferenças significativas entre os frutos de polinização aberta e dirigida tanto para peso quanto para diâmetro (Tabela 5).

As sementes obtidas com as polinizações dirigida e aberta foram classificadas como atípicas ou normais (Figura 1a). Para testar a hipótese de nulidade de que o tipo de sementes obtido independe do sistema de polinização, foi utilizado o teste de $\chi^{2}$ (Tabela 6). A proporção de sementes atípicas encontradas em frutos oriundos de 'Marubakaido' foi bastante similar entre os dois sistemas de polinização utilizados $\left(\chi^{2}=0,047, \mathrm{P}>0,70\right)$. Contudo, a hipótese da nulidade foi rejeitada quando as sementes analisadas eram oriundas de 'M.9'. O elevado valor do $\chi^{2}$ (27,31; $\mathrm{P}<0,01)$ sugere uma forte associação entre a alta quantidade de sementes atípicas (cinco vezes a quantidade de sementes normais) e a polinização dirigida no cruzamento 'M.9' X 'Marubakaido' (Tabela 6).

O efeito do sistema de polinização foi diferenciado para os dois porta-enxertos. A decomposição da Análise da Variância com o uso de contrastes ortogonais revelou valores significativos para o teste $\mathrm{F}(\mathrm{P}<0,01)$ para as variáveis peso de fruto, diâmetro de fruto, número de sementes normais, número de sementes atípicas e carpelos com sementes quando se comparou polinização dirigida com aberta em 'M.9' (Tabela 7). No entanto, a mesma análise para 'Marubakaido' revelou valores de $\mathrm{F}$ não significativos para todas as variáveis avaliadas.

\section{CONCLUSÕES}

Nas condições em foi realizado o trabalho, pode-se concluir que:

a) O período de floração do porta-enxerto Marubakaido foi mais precoce e mais prolongado em relação ao 'M.9'.

b) Os porta-enxertos Marubakaido e M.9 apresentaram baixa frutificação e produção de sementes tanto em polinização dirigida quanto em polinização aberta.

c) A quantidade de sementes atípicas foi expressivamente maior em frutos oriundos de 'M.9' no sistema de polinização dirigida. d) Houve diferenças significativas entre os sistemas de polinização no 'M.9', mas não no 'Marubakaido', para as variáveis peso de fruto, diâmetro de fruto, número de sementes normais, número de sementes atípicas e carpelos com sementes. 


\section{REFERÊNCIAS BIBLIOGRÁFICAS}

ALSTON, F.H. Incompatibility alleles and apple pollination. Acta Horticulturae, Leuven, v.423, p.119-124, 1996.

BENDER, R.J. Botânica e Fisiologia. In: Manual da cultura da macieira. Florianópolis: EMPASC, 1986. p.26-49.

BESSHO, H., SOEJIMA, J., ITO, Y., KOMORI, S. Breeding and genetic analysis of apple in Japan. In: HAYASHI, T., OMURA, M., SCOTT, N.S. (Ed.) Techniques on gene diagnosis and breeding in fruit trees. Tsukuba: Fruit Tree Research Station (FTRS), 1993.p. 231-240.

CAMARGO, U.A. Comportamento de algumas cultivares e seleções de macieira (Malus pumila Mill.) quanto à polinização na região sul do Rio Grande do Sul. 1973. 62f. Dissertação (Mestrado) - Universidade Federal de Pelotas, Pelotas, 1973.

CHAMPAGNAT, P. Dormance des bourgeons chz les végétaux ligneus. In: CÔME, D. (Ed.) Les végétaux et le froid. Paris: Hérmann, éditeurs des sciences et des arts, 1992. p.203-260.

CHILDERS, N.F. Modern fruit science. New Brunswiek: New Jersy, 1976. p.128-145.

CUMMINS, J.N. ALDWINCKLE, H.S. New resistant rootstocks from Geneva. Fruit Varieties Journal, Massachucetts, v.48, p.39, 1994.

DAYTON, D.F. Overcoming self-incompatibility in apple with killed compatible pollen. Journal of the American Society for Horticultural Science, Alexandria, v.99, p.190-192, 1974.

DENARDI, F. Porta-enxertos. In: Manual da Cultura da Macieira. Florianópolis: EMPASC, 1986. p. 92-132.

ELRFVING, D.C.; SCHEETER, I.; HUTCHINSON, A. The history of de vineland apple rootstocks. Fruit Varieties Journal, Massachucetts, v.47, p.52-58, 1993.

FAUST, M. Fruiting. In: Physiology of temperate zone fruit trees. Beltsville: A Wiley-Interscience Publication. Beltsville, 1989. p. 169-234.

FAUST, M.; ZIMMERMAN, M., T. van der ZWET. Genetic transmission of bloom date in pears. HortScience, Alexandria, v.11, p.59-60, 1976.

FERREE, D.C., CARLSON, R.F. Apple rootstocks. In: ROM, R.C.; CARLSON, R.F. (eds.). Rootstocks for Fruit Crops. New York: John Wiley \& Sons, 1987. p.107-143.

FISCHER, M. The Pilnitz apple rootstock breeding methods and selection results. Acta Horticulturae, Leuven, v.151, p.89-95, 1997.

GRANGER, R.L.; ROUSELLE, G.L., MEHERIUK, M., KHANIZADEH, S. Performance of 'Cortland' and 'McIntosh' on fourteen rootstocks in Quebec. Fruit Varieties Journal,
Massachusetts, v.46, p.114-118, 1992.

GRAUSLUND, J. Pollination experiments with selected apple cultivars. Acta Horticulturae, Leuven, v.423, p.161-165, 1996.

HAUAGGE, R., TSUNETA, M. 'IAPAR 75-Eva', 'IAPAR 76Anabela'e IAPAR 77-Carícia'- Novas cultivares de macieira com baixa exigência em frio. In: CONGRESSO BRASILEIRO DE FRUTICULTURA, 15., 1998, Poços de Caldas. Resumos..., Lavras: UFLA, 1998.p.472.

ISHIYKAWA, M.; SUZUKI, C.; KITAYAMA, H.; SATO, T.; KUDO, N. New apple cultivar 'Mellow'. Bulletin Aomori Apple Experim. Station Rep., v.27, p.99-109, 1989.

MANGANARIS, A.G.; ALSTON, F.H. Inheritance and linkage relationships of glutamate oxaloacetate transaminase in apple. 1. THE GENE Got-1, a marker for the S incompatibility locus. Theoretical Applied and Genetics, Berlin, v.74, p.154-161, 1987.

MASSERON, A., ROCHE, L. Porte-greffe du pommier Pajam ${ }^{\circledR} 1$ Lancep, Pajam ${ }^{\circledR} 2$ Cepiland deux seléctions de M.9 sans virus. Infos-Ctifl, v. 94, p.17-21, 1993.

MURNEEK, A.E. Apple pollination investigations. Columbia. University of Missouri, Agriculture Exp. Station, 1930, 47p. (Research Bulletin, 138).

PELEGRIN, M. A polinização cruzada de cultivares de macieira (Malus ssylvestris Mill.) no Planalto Catarinense. Pelotas, 1976. 64p. Dissertação - (Mestrado). Universidade Federal de Pelotas.

PETRI, J., PASQUAL, M. Polinização da macieira no alto do Rio do Peixe, Santa Catarina. Florianópolis: EMPASC, 1981, 40p. Boletim Técnico ${ }^{\circ} 1$.

PETRI, J.L., PALLADINI, L.A., SCHUCK, E., DUCROQUET, J.P.H.J., MATOS, C.S., POLA, A.C. Dormência e indução da brotação de fruteiras de clima temperado. Florianópolis: EPAGRI, 1996, 110p. Boletim Técnico, ${ }^{\circ} 75$.

ROM, R.C. Variety and cultural considerations necessary to assure adequate pollination in apple orchards. In: The indispensable pollinators. Pollination Conference, IX ${ }^{\text {th }}$, West Lafayette, 1970. Proceedings..., 1970, p.219-225.

SCHRAMM, C.C. Compatibilidade e incompatibilidade gametofítica entre as principais cultivares de macieiras (Malus domestica, Borkh.) em Pelotas. Pelotas, 1985. 58p. Dissertação - (Mestrado). Universidade Federal de Pelotas.

SEIF, S.A., HASSAN, M.M. Chilling, growing degree hours requirements, growth vigour, productivity and fruit quality of some apple cultivars under warm climatic conditions. Egyptian Journal of Horticulturae, Cairo, v.19, n.1, p.55-68, 1993.

SOLTÉSZ, M. Lows of bloom phenology by apple. Acta Horticulturae, Leuven, v.437, p.451-456, 1997. 
STEEL, R.G.D., TORRIE, J.H. Principles and procedures of statistics - A biometrical approach. 2.ed. New York: McGraw-Hill Book, 1980, 633p.

TRAJKOVSKI, V., ANDERSON, G. Växtförä dling ar grundstammar. Annual Report for Balsgärd Research Station for 1987,1988, p.23-26.

WEBSTER, A.D. A review of fruit tree rootstock research and development. Acta Horticulturae, Leuven, v.451, p.53-73, 1997.

WEBSTER, A.D., TOBUTT, K.R., JAMES, D.J., EVANS, K.M., ALSTON, F.A. Rootstock breeding and orchard testing at horticulture research international - East Malling. Acta
Horticulturae, Leuven, v. 451, p.83-88, 1997.

WERTHEIM, S.J. Methods for cross pollination and flowering assessment and their interpretation. Acta Horticulturae, Leuven, v.423, p.237-241, 1996.

WHILLIAMS, R.R., MAIER, M. Pseudo-compatibility afterpollination of the Cox's Orange Pippim. The Journal of Horticultural Science, Ashford, v.52, p.475-483, 1977.

ZAGAJA, S.W. Performance of two apple cultivars on P. series dwarf rootstocks. Acta Horticulturae, Leuven, v.114, p.162-169, 1980. 